\title{
DECENTRALIZATION FROM THE REGIONAL PERSPECTIVE: AN APPLICATION OF AHP
}

\author{
(Iwan J. Azis) \\ Cornell University \& University of Indonesia
}

Ideas ranging from 'decentralization' and 'bottom-up planning' are recently on the high agenda of regional development in many developing countries including Indonesia, although in many cases much of this still remains in the form of concepts rather than as fully implemented operational mechanisms. Despite the urgent need for having these concepts implemented, determining the exact nature of decentralization suitable for implementation will inply a rather complex analysis. Furthermore, problems arise in one region could be different from those found in others. Yet, while many studies often view decentralization process from the national perspective, very few are based on the vision from the region's interest.

In this paper the author attempts to unravel various aspects pertaining to the problems and issues of decentralization in Indonesia viewed from the regional perspective, based on a case study of Riou province in the northern part of Sumatera. The Analytic Hierarchy Process (AHP) is adopted for this purpose. The province of Riau is selected as the case region due to its unique position in the national economy, that is, being one of the largest contributors to the nation's foreign exchange (oil) revenue, and the fact that Riau is the only province directly involved in the recent development of the so-called "growth triangle" concept (Singapore-Johor-Batam).

In particular, two topics are to be discussed: first, the nature and process of decentralization viewed from the regional perspective, and second, problems pertaining to the accomplishment of predetermined targets in the planning process in Riau.

\section{DESCRIPIION OF THE CASE REGION}

Riau is chosen as a case region for several reasons. On the one hand, it is a particularly dynamic area from both an economic and a demographic perspective: On the other hand, the particular nature of much of the economic growth - generated through large-scale, "enclave" type of investments - has led many to question about the true interaction between this economic dynamism and the social welfare of the broad base of the population. Due to the high degree of central control over many of these "enclave" enterprises, Riau is also a particularly interesting location to examine development in the context of local 
initiative, the corresponding patterns of decentralization of authority and the role actually being played by the local government. The resource-based nature of most of the major economic activities has also placed Riau in the forefront to emerging concerns about ecological or environmental linkages within the concept of "susiainable development."

The economic role of Riau is striking. With less than two percent of the nation's population, up to the mid 1980s the province contributed roughly one-third of the nation's export revenues through its dominance of oil exports foil is the region's most abundant natural resource). Even though this has fallen somewhat in recent years, due to the growth in manufacfured exports and the opening up of other new resource-based activity throughout the nation. Riau's contribution to national exporits still remains far in excess of its population share.

Land, and associated primary secior production, is probably the most striking characteristic of Riau. Even with rapid population growth (4.2 percent annually between 1980 and 1990), average population density remains among the lowest in the nation. Close to 60 percent of the workforce are primarily dependent on agriculture, a figure which is well above the national average, and most of these are small-scale farmers dependent mainly on dry-land food crops (the scope of imigation is extremely limited) and small-holder rubber and coconut as the basic means of livelihood.

The small-scale primary production which characterized the mass of the people can, however, be contrasied with more modern large-scale undertakings in the forestry and plantation sectors. Riau's vast stretches of rain forest and secondary forest have been subject to massive exploitation, initially as a source of logs and, following the ban on log exports in the early 1980s, of sawn timber. plywood and other wood-based products. In recent years there has been a move to establish large-scale plantation enierprises by both the public and private sectors focusing on what is seen to the particularly lucrative domestic and export markets for palm oil and their corresponding products. From only 7000 hectares in 1986, production area for palm oil (virtually all in estates) has now reached well over 100,000 hectares and sources in Riau suggest that over 300,000 hectares are in various stages of development.

Another recent endeavor has been the esiablishment of timber estates (hutan tanaman industri) focusing on the production of fast growing species to feed the developing pulp and paper industry. One major pulp and paper factory has already been established in Riau and has been awarded a concession of roughly 200.000 hectares for timber production. Others are programmed to follow. 
decision-making based on sectoral-vertical- departmental outhority, and another based on a more autonomous- decentralized decision-making line. Riau is no exception. However, unlike in many other regions, Riau is an oll-rich province and one which makes a substantial contribution to total nationai export revenue. Due. however, to the centralized State control of the oil and gas sector, virtually all oil revenues accrue to the center and only a small portion of it is actually returned to the region in the form of various grants and transfers.

Despite the fact that such a condition is expected for a nation with a sirong commitment to a principle of a Unitary State, it is not unnatural to expect some growing concern with limitations on the volume of funds actually available for the province's development on the one hand and with the huge revenues being generated by enclaves within the region on the other.

The lack of decentralization is often offered as the main explanation. Only in the past few years, however, have efforts to promote further decentralization been escalated. Yet this is not easy and there are a number of necessary conditions for a more decentralized system that need to be fulfilled. One such condition reflects the capability of regional siaff and personnel, and this is one which is considered critical for a dynamic region such as Riau. Yet, general observations suggest that this condition is still far from being met. Recruitment of new staff for the Bappedo office who can meet sufficient standards of quality is becoming increasingly more difficult.

Another important factor is obviously the insufficiency of development funds in the region. Greater autonomy will mean little without sufficient funds' to support the plans and programs initiated by the region. There are also underlying concerns that obtaining greater autonomy and decentralization at this stage could also be detrimental to the region's interest. This is based on the idea that, despite potential benefits, further decentralization will also create additional costs that will need $x \$ 3$ to be borne by the region itself. It is based on this premise a cost-benefit framework of decentralization is adopted for this analysis.

Efforts to meet necessary conditions for further decentralization in Riau are already being undertaken, but so far with little success. The non-optimal allocation system of funds from the center to the region is likely to further reinforce the difficulties of further decentralization. Even so, perhaps the most critical issue in the case of Riau is the fact that development planning and implementation in many areas within the province are determined largely by centrally located authorities and interests. Batam and Binton are the most notable examples as they are managed by a specially assigned and more or less independent authority. In this respect. Batam can be considered as virtually 'untouchable' by the provincial 


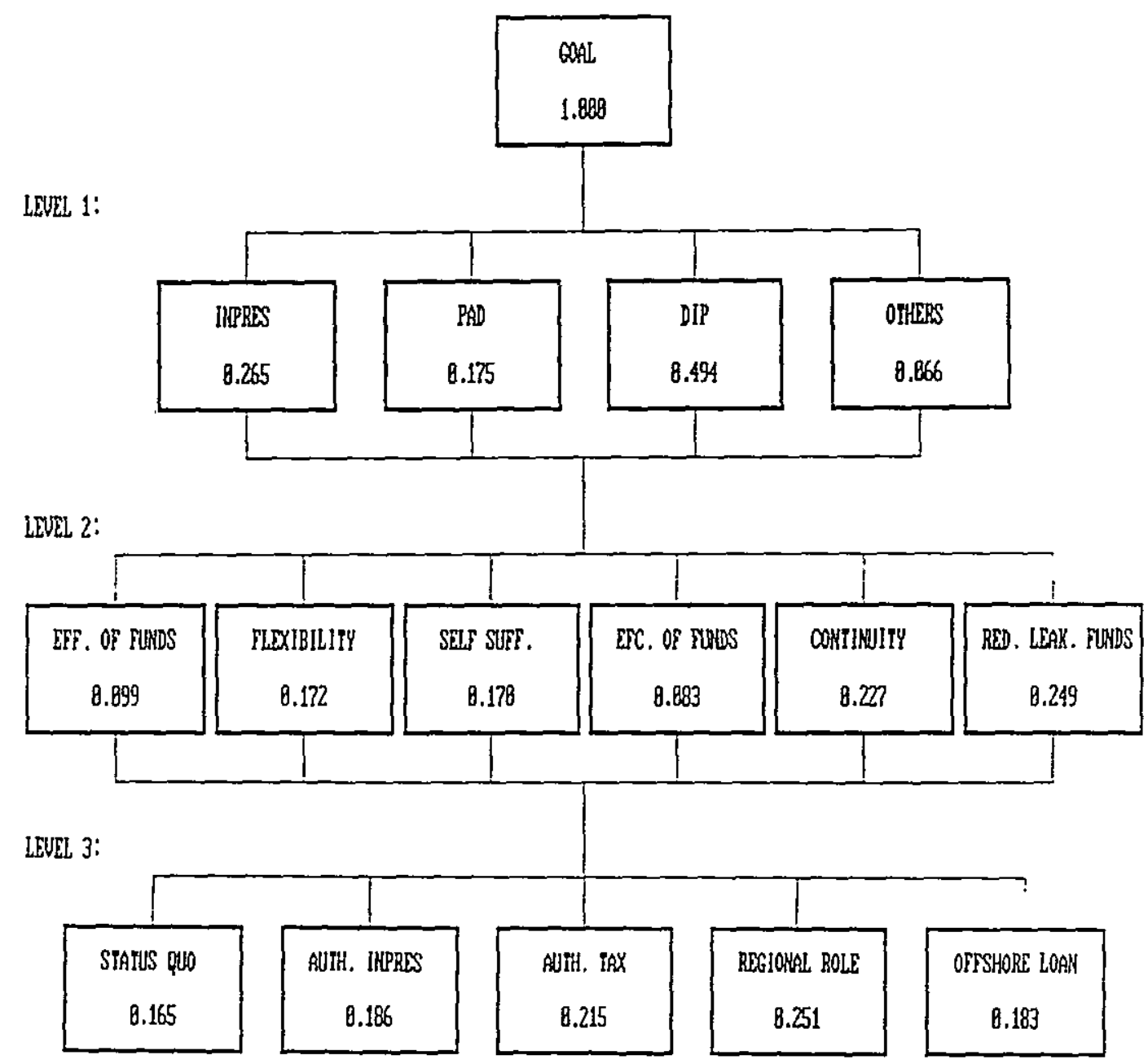

CONSISTENCY INDEX : 8.13

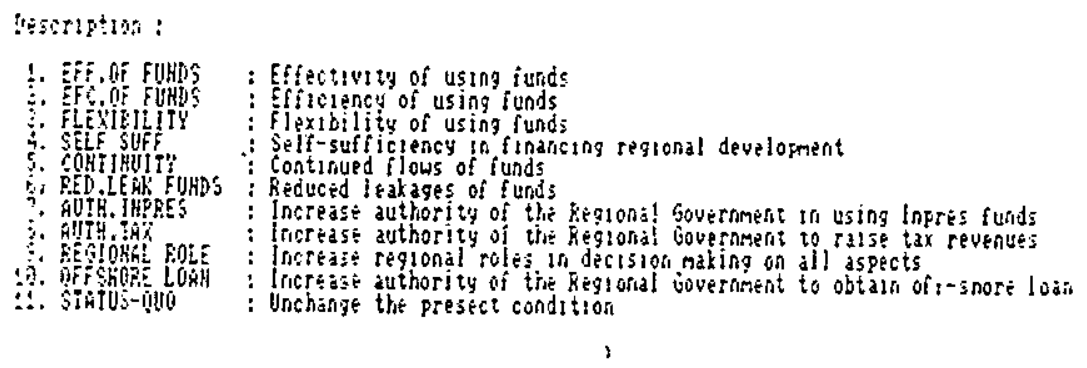




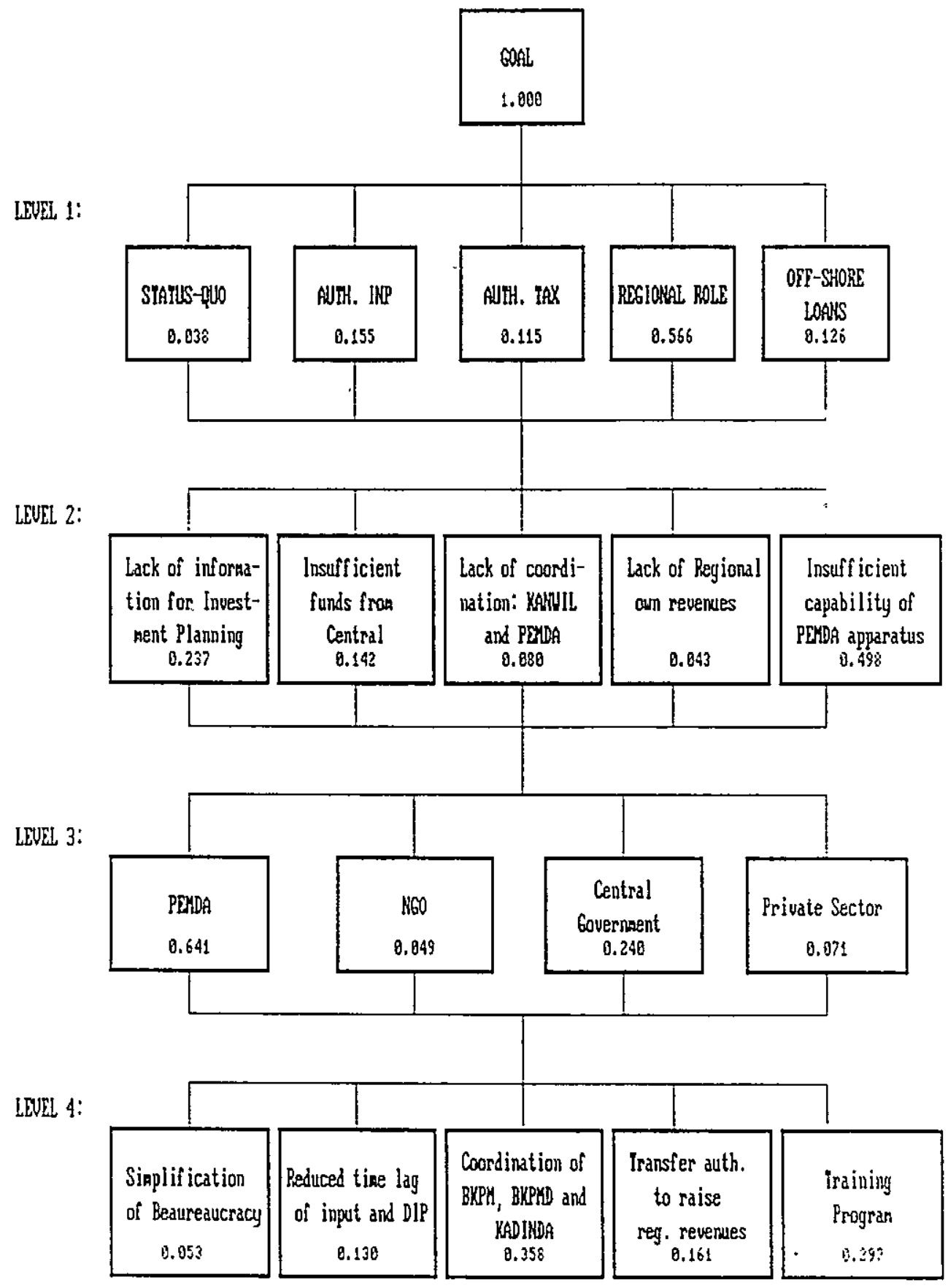




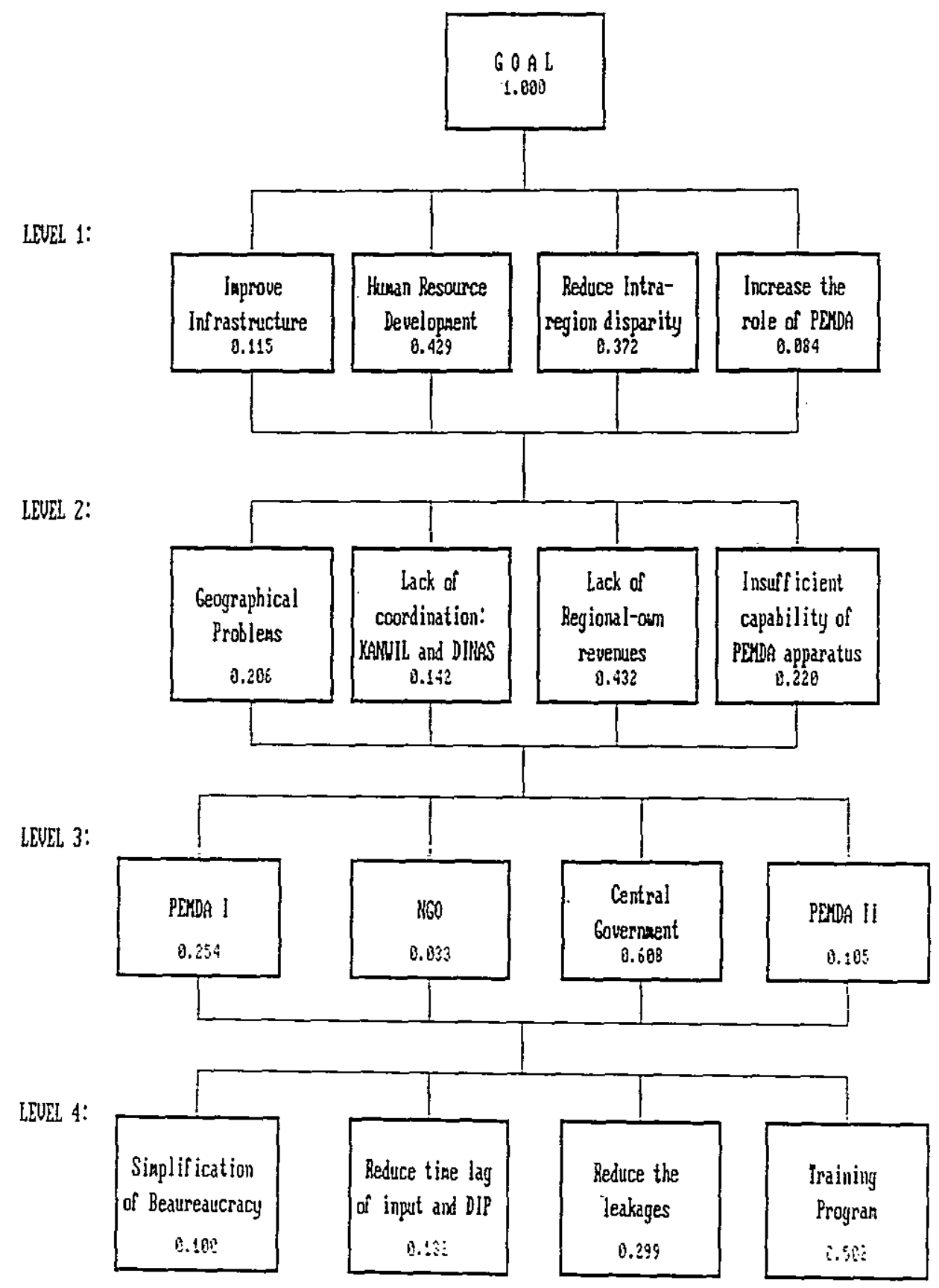

